\title{
Preliminary Design of Winged Experimental Rocket by University Consortium
}

\author{
By Masashi WAKITA ${ }^{1)}$, Koichi YONEMOTO ${ }^{1)}$, Tomoki AKIYAMA ${ }^{1)}$, Shigeru ASO ${ }^{2)}$, \\ Yuji KOHSETSU ${ }^{2)}$, and Harunori NAGATA ${ }^{3)}$ \\ 1) Department of Mechanical and Control Engineering, Kyushu Institute of Technology, Fukuoka, Japan \\ ${ }^{2)}$ Department of Aeronautics and Astronautics, Kyushu University, Fukuoka, Japan \\ ${ }^{3)}$ Graduate School of Engineering, Hokkaido University, Hokkaido, Japan
}

(Received April 24th, 2008)

\begin{abstract}
The project of Winged Experimental Rocket described here is a proposal by the alliance of universities (University Consortium) expanding and integrating the research activities of reusable space transportation system performed by individual universities, and is the proposal that aims at flight proof of the results of advanced research conducted by the universities and JAXA using the university-centered experimental launch systems. This paper verifies the validity of the winged experimental rocket by surveying the technical issues that should be demonstrated and by estimating the airframe scale, weight and finally the total cost. The development schedule of this project was set to five years, where two airframes of different scales will be developed to minimize the risks. A 1.5-meter-long airframe will be first manufactured and conduct flight tests in the third year to verify the design issues. Then, a 2.5 -meter-long airframe will be finally developed and conduct a complete flight demonstration of various research issues in the fifth year.
\end{abstract}

Key Words: Winged Rocket, University Consortium

\section{Introduction}

Based on the long term vision of expanding ideal society through aerospace technology for the next twenty years, JAXA (Japan Aerospace Exploration Agency) will expand core researches and developments toward the future manned space transportation system not only by keeping the strong relations with aerospace industries but also initiating wide collaborations with universities and other research institutes ${ }^{1,2)}$.

In the Japanese experimental spaceplane project HOPE-X (H-2 Orbiting Plane Experimental), many essential technologies for future manned space transportation system have remarkably advanced. Beside the research and development, a number of flight demonstrations such as OREX (Orbital Reentry Experiment), HYFLEX (Hypersonic Flight Experiment), ALFLEX (Automatic Landing Experiment) and HSFD (High-Speed Flight Demonstration) have been conducted one after another. In JAXA, the flight experiments of vertical takeoff and landing rocket called RTV (Reusable Test Vehicle) that aims at realizing reusable sounding rocket is currently in progress ${ }^{3)}$ and the flight experiment of LIFLEX (Lifting Body Flight Experiment) will be scheduled in the near future ${ }^{4)}$. However, such joint development projects of JAXA in collaboration with aerospace industries generally require long time span and high expenses. Since careful discussions are always necessary for every decision making in the contract, such circumstances give rise to a sense of stagnation of the current research and development projects. Recently JAXA has been groping collaborations with universities, or the alliance of universities (University Consortium) and institutes to break down such a stagnation feeling after the freeze of HOPE-X project.

The advantages of the project conducted by the University Consortium are considered as follows:

- A lot of innovative research outcomes are expected from the universities. The reusable launch vehicle designed and developed by the University Consortium provides many chances to prove the new ideas and promote positivism researches.

- Since the activities of the University Consortium are not so much restricted by contracts unlike aerospace industries, the project can be steered as flexible as possible preparing for unexpected problems. This will result in a high cost performance that the aerospace industries can not afford to do.

The project of Winged Experimental Rocket described here is a proposal by the University Consortium expanding and integrating the research activities of reusable space transportation system performed by individual universities ${ }^{5-7)}$, and is the proposal that aims at flight proof of the results of elementary research conducted by the universities and JAXA using the university-centered experimental launch systems ${ }^{8,9)}$.

In this paper, conceptual designs of winged experimental rocket is studied for the purpose of demonstrating the advanced technologies (aerodynamics, structure, guidance and control, and recovery technique, etc.) at early research and development stage by means of actual flight tests. In addition to the design studies, a development plan is proposed. 


\section{Preliminary Design of Winged Experimental Rocket System}

\subsection{Project outline}

Based on the past program of JAXA toward the future manned space transportation system as mentioned previously, authors are looking for a new development approach of winged experimental rocket by the University Consortium. Technical key issues to achieve the manned space transportation system are considered as follows:

- high-reliability design technology

- state-of-the-art composite structure

- health monitoring of air flame

- abort flight control technology

- high-reliability propulsion system

As a flight test bed to verify these technical issues, this project aims at the development of the winged experimental rocket that offers flight chances for demonstration as many as possible.

One of the realistic approaches that achieve reusable space transportation system whether manned or unmanned is the idea of flight envelope expansion. The flight envelope expansion is a method of enlarging the flight affordable trajectory step by step to verify the required technological issues. The trajectory of reusable space transportation system has a wide range from ground to space. From the viewpoint of the university-centered development of this project, the range of trajectory is limited to launch phase and landing phase to verify the related technological issues.

HIMES (HIghly Maneuverable Experimental Space vehicle), which was proposed by JAXA/ISAS (Institute of Space and Astronautical Science), is selected as a basic airframe ${ }^{10)}$. HIMES airframe is shown in Fig.1.

To minimize the development risks of winged experimental rocket, two kinds of airframe with different scales are developed. Fig. 2 shows the achievable altitudes in terms of the airframe scales. The airframe of $1.5 \mathrm{~m}$ body length will be first developed. The target altitude of this airframe is from $500 \mathrm{~m}$ to $1,000 \mathrm{~m}$. The purpose of this

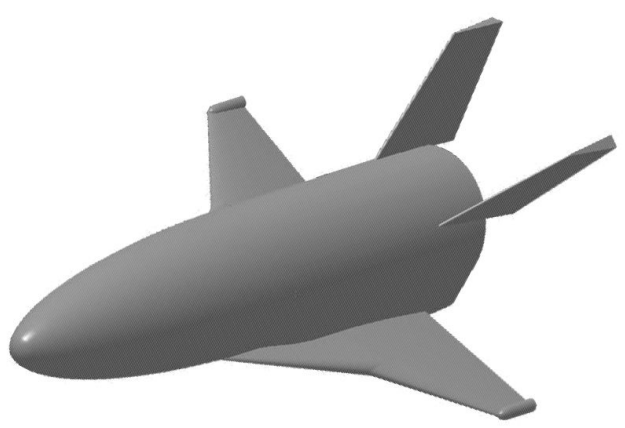

Fig. 1. HIMES airframe

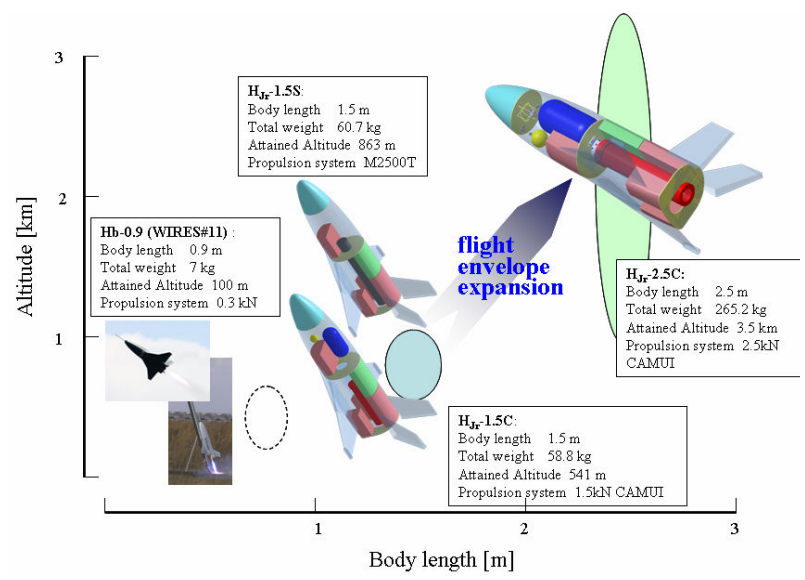

Fig. 2. Scale of winged experimental rockets

development is to verify the feasibilities of system and structure design as a bus system, and to establish the flight hardware and equipments developed for the technical demonstration issues. Then the airframe of 2.5 $\mathrm{m}$ body length will be developed for full flight demonstration from the altitude of $1,000 \mathrm{~m}$ to $3,000 \mathrm{~m}$.

\subsection{Technical issues for demonstration}

Typical technical issues to be demonstrated by the winged experimental rocket are shown in Table 1. Many universities have been studying the technical issues individually.

Table 1. Technical issues

\begin{tabular}{lll}
\hline & \multicolumn{1}{c}{ Technical issues } & Universities \\
\hline 1. & GA/SQP optimal trajectory generation algorithm & Kyushu Institute of Technology \\
2. & $\begin{array}{l}\text { Low-cost navigation and control system composed of COTS (commercial-off-the-shelf) } \\
\text { products }\end{array}$ & Kyushu Institute of Technology \\
3. & High dynamics GPS measurement system using open source architecture & $\begin{array}{l}\text { Tokyo University of } \\
\text { and Technology }\end{array}$ \\
& & Kyushu Institute of Technology \\
4. & Composite tank made of ceramic compound CFRP & The University of Tokyo \\
5. & CFRP health monitoring system using fibre optic sensors & Hokkaido University \\
6. & High maneuver hybrid rocket system & Kyushu Institute of Technology \\
7. & Parafoil recovery system &
\end{tabular}

Table 2. Mass breakdown of winged experimental rockets

\begin{tabular}{|c|c|c|c|c|c|c|}
\hline $\begin{array}{c}\text { Body length } \\
L_{\mathrm{b}}[\mathrm{m}] \\
\end{array}$ & $\begin{array}{c}\text { Structure } \\
M_{\text {str }}[\mathrm{kg}] \\
\end{array}$ & $\begin{array}{c}\text { Recovery system } \\
M_{\mathrm{rec}}[\mathrm{kg}] \\
\end{array}$ & $\begin{array}{c}\text { Electric device } \\
M_{\text {elect }}[\mathrm{kg}]\end{array}$ & $\begin{array}{c}\text { Navigation and control } \\
M_{\mathrm{ngc}}[\mathrm{kg}]\end{array}$ & $\begin{array}{l}\text { Actuator } \\
M_{\text {act }}[\mathrm{kg}] \\
\end{array}$ & $\begin{array}{c}\text { Spear weight } \\
M_{\text {spr }}[\mathrm{kg}]\end{array}$ \\
\hline 1.5 & 19.3 & 11.6 & 3.9 & 3.0 & 3.9 & 9.8 \\
\hline 2.5 & 69.2 & 41.5 & 13.8 & 3.0 & 13.8 & 44.2 \\
\hline
\end{tabular}




\subsection{Airframe sizing}

\subsubsection{Mass estimation}

The empirical equations of mass prediction are shown as follow:

Structure:

$$
\begin{aligned}
& M_{\text {str }}=7 L_{\mathrm{b}}^{2.5} \\
& M_{\text {rec }}=0.6 M_{\text {str }} \\
& M_{\text {elect }}=0.2 M_{\text {str }}
\end{aligned}
$$

Recovery system:

Navigation and Control: $M_{\mathrm{ngc}}=3$

Actuator:

$M_{\text {act }}=0.2 M_{\text {str }}$

Spear weight:

$$
M_{\mathrm{spr}}=0.2\left(M_{\mathrm{str}}+\ldots+M_{\mathrm{act}}\right)[\mathrm{kg}]
$$

The mass of structure $\left(M_{\text {str }}\right)$ is estimated as an empirical function of the body length based on the experimental vehicles in the past as shown in Fig. 3. The mass of recovery system $\left(M_{\text {rec }}\right)$, electric devices $\left(M_{\text {elect }}\right)$, and actuator $\left(M_{\text {act }}\right)$ are estimated as a function of structure mass respectively. The navigation and control system has $3 \mathrm{~kg}$ mass. Table 2 shows the mass breakdown of the

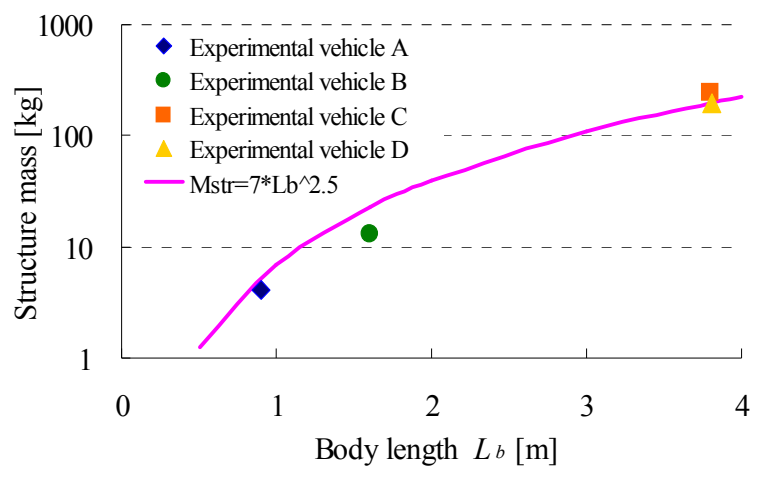

Fig. 3. Structure mass as a function of body length winged experimental rockets with $1.5 \mathrm{~m}$ and $2.5 \mathrm{~m}$ body length respectively.

\subsubsection{Selection of propulsion system}

The model rocket motors and CAMUI hybrid rockets are employed for the propulsion system of winged experimental rockets. The achievable altitude of the winged experimental vehicles for both the $1.5 \mathrm{~m}$ and 2.5 $\mathrm{m}$ body length are estimated respectively. The initial flight path angle is 85 degrees.

Table 3 summarizes the engine performances and the estimated achievable altitudes for the six types of model rocket motors (K1999N, L1500T, M1600R, M2500T, N2000W and N4000), which are commercially-supplied in United States. These model rocket motors have relatively large total impulse, which have not been imported in Japan yet. Therefore it is necessary to have a negotiation with the METI (Ministry of Economy, Trade and Industry) about the import license and customs procedures.

The winged experimental rockets of $1.5 \mathrm{~m}$ body length that have rocket motors of M1600R or M2500T can achieve the altitude more than $400 \mathrm{~m}$. On the other hand, the winged experimental rocket of $2.5 \mathrm{~m}$ body length has very poor launch performance even if using the maximum model rocket motor.

Table 4 shows the engine performances and the estimated attained altitudes for a variety of CAMUI hybrid rockets. It is shown that the winged experimental rocket of $1.5 \mathrm{~m}$ body length can achieve the altitude from 500 to $1,000 \mathrm{~m}$ by using $1.5 \mathrm{kN}$ or $2 \mathrm{kN}$ thrust CAMUI

\begin{tabular}{|c|c|c|c|c|c|c|}
\hline \multirow{3}{*}{ Motor type } & Thrust & Combustion time & Total impulse & Propellant mass & Attain & itude \\
\hline & \multirow{2}{*}{$T[\mathrm{~N}]$} & \multirow{2}{*}{$t[\mathrm{~s}]$} & \multirow{2}{*}{$I_{t}[\mathrm{kN} \cdot \mathrm{s}]$} & \multirow{2}{*}{$M_{\text {prop }}[\mathrm{kg}]$} & \multicolumn{2}{|c|}{$H_{\max }[\mathrm{m}]$} \\
\hline & & & & & $\mathrm{L}_{\mathrm{b}}=1.5[\mathrm{~m}]$ & $\mathrm{L}_{\mathrm{b}}=2.5[\mathrm{~m}]$ \\
\hline K1999N & 1,999 & 1.45 & 2.6 & 3.0 & 90 & 2 \\
\hline $\mathrm{L} 1500 \mathrm{~T}$ & 1,500 & 3.5 & 5.1 & 4.7 & 245 & 0 \\
\hline M1600R & 1,600 & 4.4 & 7.1 & 6.7 & 451 & 0 \\
\hline $\mathrm{M} 2500 \mathrm{~T}$ & 2,500 & 4.0 & 10.2 & 8.0 & 863 & 51 \\
\hline $\mathrm{N} 2000 \mathrm{~W}$ & 2,000 & 7.0 & 12.4 & 12.4 & 1,269 & 79 \\
\hline N4000 & 4,000 & 4.1 & 16.5 & 13.7 & 1,757 & 236 \\
\hline
\end{tabular}
hybrid rockets, and the vehicle of $2.5 \mathrm{~m}$ body length can achieve the altitude of $3,000 \mathrm{~m}$ by using the $8 \mathrm{kN}$ thrust.

\begin{tabular}{|c|c|c|c|c|c|c|}
\hline \multirow{2}{*}{$\begin{array}{l}\text { Motor } \\
\text { type }\end{array}$} & Body length & Thrust & Combustion time & Total impulse & Propellant mass & Attained altitude \\
\hline & $L_{b}[\mathrm{~m}]$ & $T[\mathrm{~N}]$ & $t[\mathrm{~s}]$ & $I_{t}[\mathrm{kN} \cdot \mathrm{s}]$ & $M_{\text {prop }}[\mathrm{kg}]$ & $H_{\max }[\mathrm{m}]$ \\
\hline \multirow{10}{*}{ CAMUI } & \multirow[b]{2}{*}{1.5} & 1,000 & 4.5 & 4.5 & 3.5 & 144 \\
\hline & & 1,500 & 5.5 & 8.2 & 6.4 & 541 \\
\hline & \multirow{8}{*}{2.5} & 2,500 & 7.1 & 17.7 & 13.7 & 121 \\
\hline & & 3,500 & 8.4 & 29.3 & 22.8 & 498 \\
\hline & & 4,500 & 9.5 & 42.7 & 33.2 & 1,026 \\
\hline & & 5,500 & 10.5 & 57.7 & 44.8 & 1,666 \\
\hline & & 6,500 & 11.4 & 74.1 & 57.6 & 2,408 \\
\hline & & 7,500 & 12.2 & 91.9 & 71.4 & 3,141 \\
\hline & & 8,000 & 12.6 & 101.2 & 78.6 & 3,523 \\
\hline & & 8,500 & 13.0 & 110.8 & 86.1 & 3,914 \\
\hline
\end{tabular}

Table 3. Model rocket engine and altitude performance

Table 4. Engine CAMUI hybrid rocket and altitude performance 


\subsubsection{Candidates of winged experimental rockets}

Based on the calculation of altitude performance mentioned above, three candidates of winged experimental rocket are selected as shown below:

$\begin{array}{lll}\mathrm{H}_{\mathrm{Jr}}-1.5 \mathrm{~S}: & \text { Body length } & 1.5 \mathrm{~m} \\ & \text { Total weight } & 60.7 \mathrm{~kg} \\ & \text { Attained Altitude } & 863 \mathrm{~m} \\ & \text { Propulsion system } & \text { M2500T } \\ \mathrm{H}_{\mathrm{Jr}}-1.5 \mathrm{C}: & \text { Body length } & 1.5 \mathrm{~m} \\ & \text { Total weight } & 58.8 \mathrm{~kg} \\ & \text { Attained Altitude } & 541 \mathrm{~m} \\ \mathrm{H}_{\mathrm{Jr}}-2.5 \mathrm{C}: & \text { Propulsion system } & \text { CAMUI 1.5kN } \\ & \text { Body length } & 2.5 \mathrm{~m} \\ & \text { Total weight } & 265.2 \mathrm{~kg} \\ & \text { Attained Altitude } & 3.5 \mathrm{~km} \\ & \text { Propulsion system } & \text { CAMUI } 2.5 \mathrm{kN}\end{array}$

Three-views drawing and equipment arrangement of $\mathrm{H}_{\mathrm{Jr}}-2.5 \mathrm{C}$ is shown in Fig.5.

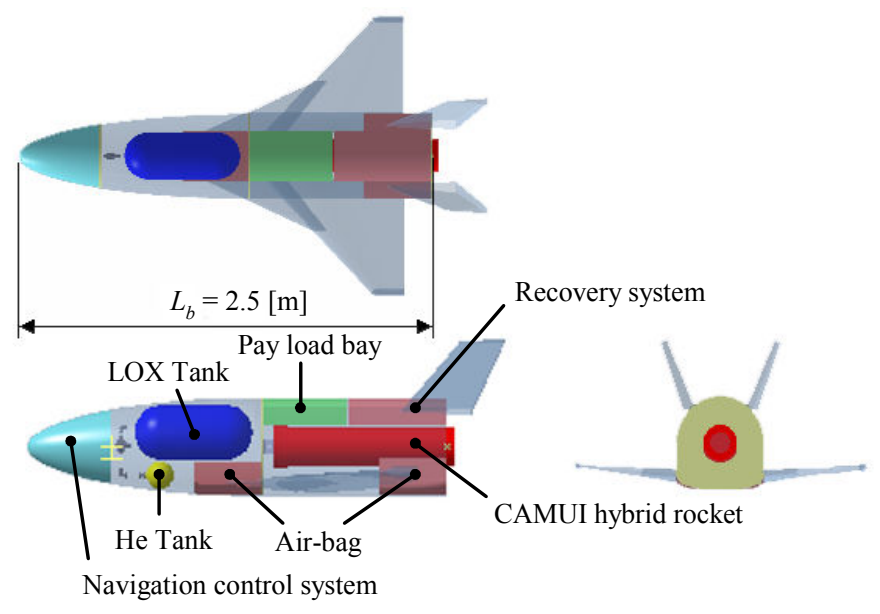

Fig. 5. Three-views drawing and equipment arrangement of $\mathrm{H}_{\mathrm{Jr}}-2.5 \mathrm{C}$

\subsection{System configuration}

\subsubsection{Body structure}

Figure 6 shows the structure concept for the winged experimental rocket of $2.5 \mathrm{~m}$ body length. As previously mentioned, the airframe shape is HIMES proposed by JAXA/ISAS. The main structure consists of nose, main body, main wing, and tail wing, most of the panels of which are made from CFRP (Carbon Fiber Reinforced Plastics). The engine mount is a truss structure.

\subsubsection{CAMUI hybrid rocket}

CAMUI is a hybrid rocket using a new combustion method developed by Hokkaido University ${ }^{11)}$. "CAMUI" was named by abbreviating this new method "Cascaded Multistage Impinging-jet." Fig. 7 shows the combustion-chamber concept of CAMUI hybrid rocket. Liquid oxidizer injected into the combustion chamber collides with the fore-end of the first stage of fuel blocks to generate combustion gas. The gas flows downstream through two ports in the first block and, then, collides with the fore-end of the second block. The aim of this mechanism is to accelerate heat transfer to the solid fuel

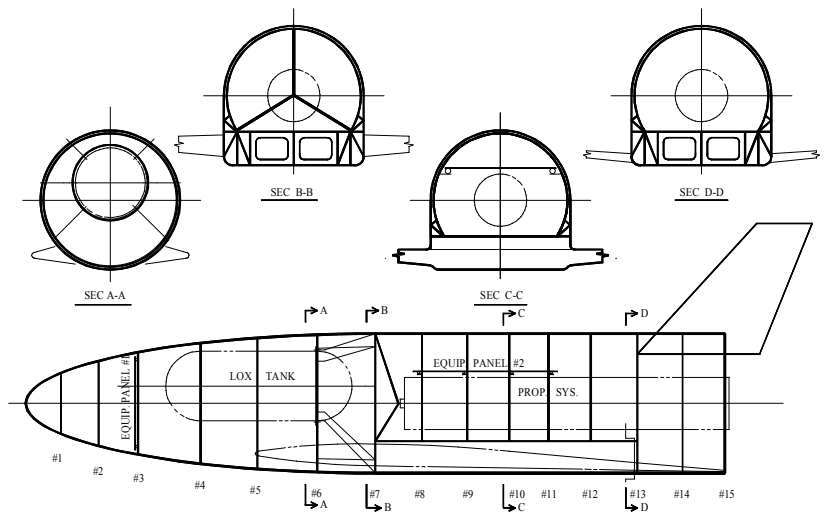

Fig. 6. Structure concept for winged experimental rocket of $2.5 \mathrm{~m}$ body length

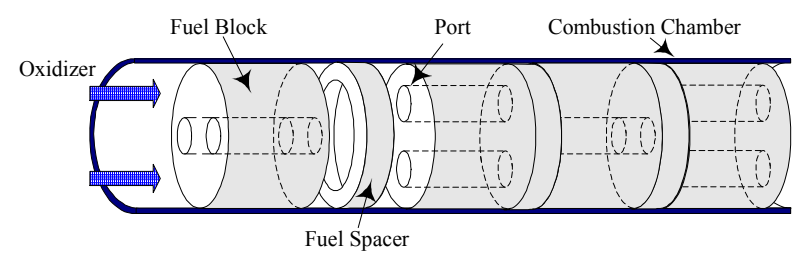

Fig. 7. Combustion-chamber concept of CAMUI hybrid rocket

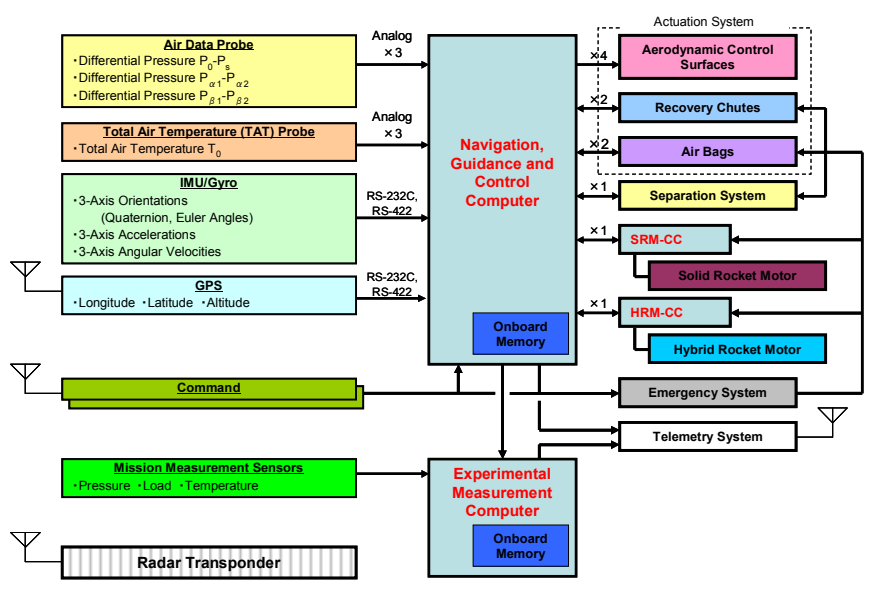

Fig. 8. Navigation, guidance and control system

using the impinging jet. By the new combustion method CAMUI adopted, one can increase the thrust density (i.e., thrust per unit volume of the combustion chamber) without limit theoretically by segmenting the fuel block into a number of thin blocks.

\subsubsection{Navigation control system}

Figure 8 shows the block diagram of navigation, guidance and control system. COTS (Commercial-off-the-shelf) computer and sensors are employed for the system to reduce costs.

The ready-made GPS receiver used in the flight environment of the actual rocket such as H-IIA is very large and expensive. For this reason, JAXA/ISAS develops a GPS receiver for sounding rockets using open source architecture named GP4020 in colaboration with Tokyo University of Marine Science and Technology and a venture company Spacelink. GPS receiver circuit board (SuperStar II shown in Fig. 9), which is supplied by the Novatel Inc., is used for the GP4020. High dynamic 


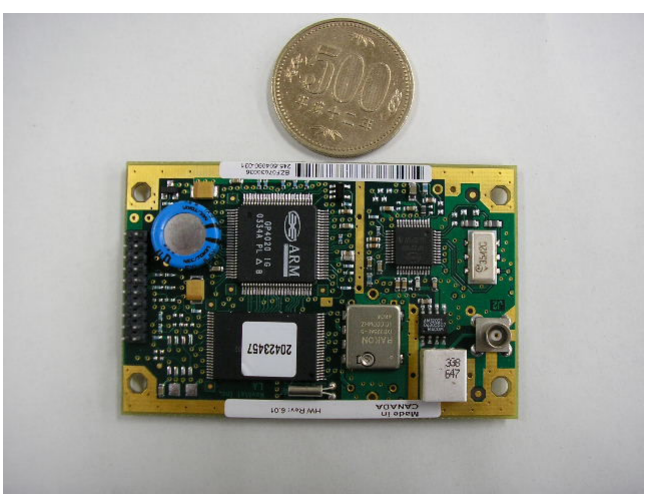

Fig. 9. GPS receiver circuit board (SuperStar II)

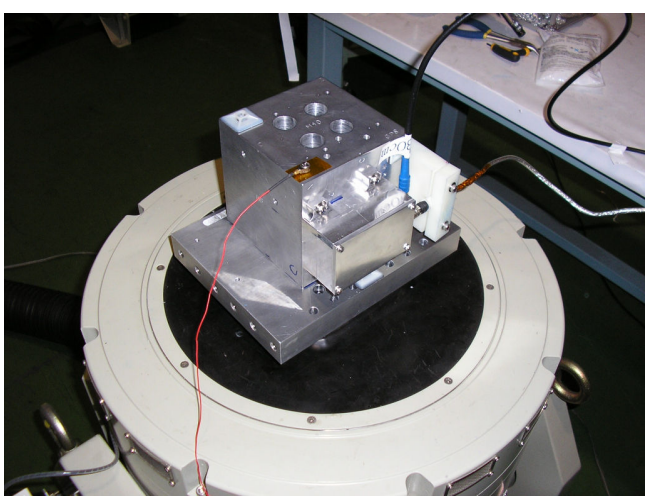

Fig. 10. Impact vibration test of GP4020

evaluation tests of signal processing using GPS simulator and impact vibration tests that simulate rocket flight environment (Fig. 10) have been conducted to give promising results as expected.

The inertial measurement unit Micro-GAIA TA7801 and the vertical gyro NAV420 are the candidates of low-cost and light commercial-off-the-shelf sensors.

\subsubsection{Recovery system}

In recovery process of the winged experimental rockets, a drogue chute is first deployed to reduce the flight speed. Then a parafoil is deployed to guide the rockets to the aiming point. Three air bags, the one of which located at the forward position and the two at the rear end position of the body, are finally deployed just before landing to avoid damage from ground. Table 5 shows the specification of parafoil.

Table 5. Specification of parafoil

\begin{tabular}{lcc}
\hline Wing area & 28 & {$\left[\mathrm{~m}^{2}\right]$} \\
Glide ratio & 4.3 & {$[\mathrm{NA}]$} \\
Deployment impact & 6 & {$[\mathrm{G}]$} \\
Weight & 17 & {$[\mathrm{~kg}]$} \\
Maximum operation weight & 160 & {$[\mathrm{~kg}]$} \\
Maximum speed & 77 & {$[\mathrm{~m} / \mathrm{s}](\mathrm{EAS})$} \\
\hline
\end{tabular}

\subsection{Flight trajectories and warning area}

The flight trajectories of the winged experimental rocket $\mathrm{H}_{\mathrm{Jr}}-2.5 \mathrm{C}$ is calculated using 6 DoF flight

\section{A) Normal return trajectory \\ B) Max. downrange trajectory \\ C) Max. clossrange trajectory}

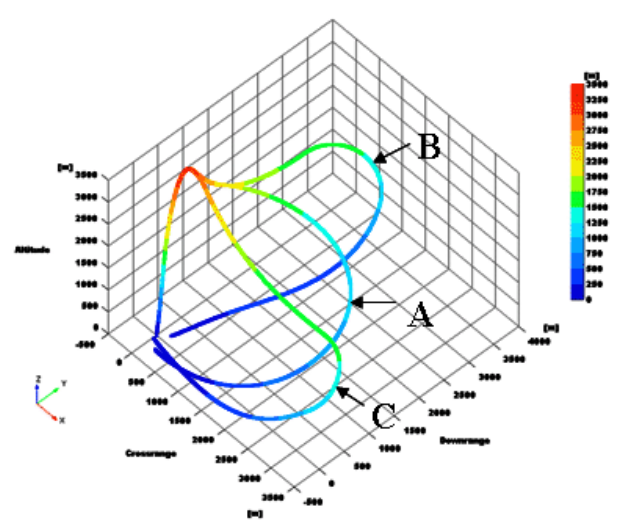

3D birds-eye view

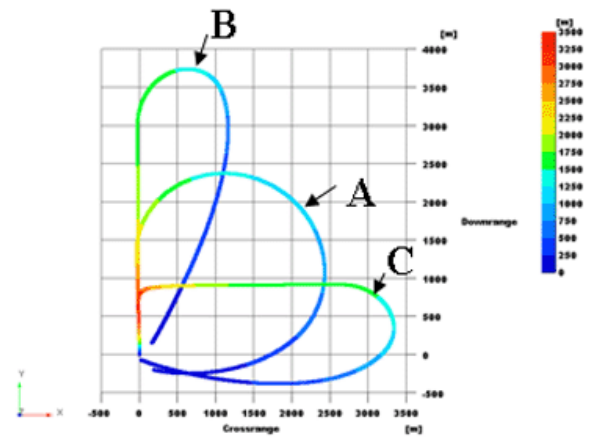

2D plan view

Fig. 11. Flight trajectories

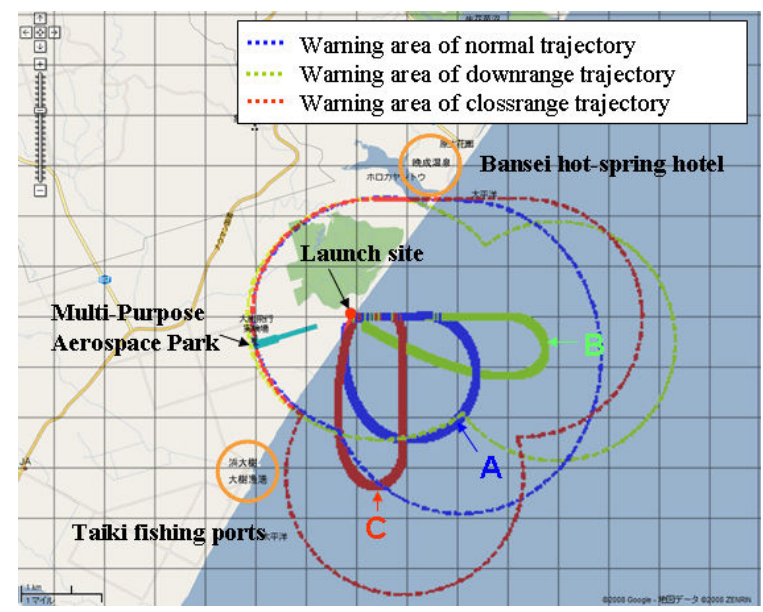

Fig. 12. Area map around the Multi-Purpose Aerospace Park of

Taiki-cho in Hokkaido

simulation program as shown in Fig.11. The experiment winged rocket reaches the apogee of $3.3 \mathrm{~km}$ in 33 seconds after the ignition. The trajectory A in Fig. 11 shows a fly back path by keeping the bank angle constant. The trajectory $\mathrm{B}$ is a maximum downrange flight path, and the $\mathrm{C}$ is a maximum cross range flight path.

The candidate launch site is located at the Pacific coast 
near the Multi-Purpose Aerospace Park of Taiki-cho in Hokkaido. The launch azimuth is assumed eastward to the ocean. In case of emergency, the winged experimental rocket deploys first the drogue chute and then the Parafoil to abort the mission. The warning area is defined based on the following assumptions.

- The maximum wind speed is $8 \mathrm{~m} / \mathrm{s}$

- The sink rate of the Parafoil is $5 \mathrm{~m} / \mathrm{s}$

- The parafoil is deployed lower than the altitude of $1,500 \mathrm{~m}$

Figure 12 shows the flight trajectories and the warning area on the map around the Multi-Purpose Aerospace Park of Taiki-cho. The outer envelope of the dotted lines corresponds to the warning area, where the important ground installations such as the hot-spring hotel and Taiki fishing ports are not included.

\section{Development Schedule}

Figure 13 shows the development schedule of the winged experimental rockets. The development period is assumed five years. The $\mathrm{H}_{\mathrm{jr}}-1.5 \mathrm{C}$ will be developed in three years and perform the flight test in the third year. Then the $\mathrm{H}_{\mathrm{jr}}-2.5 \mathrm{C}$ will be developed in three years and perform the flight demonstration in the fifth year.

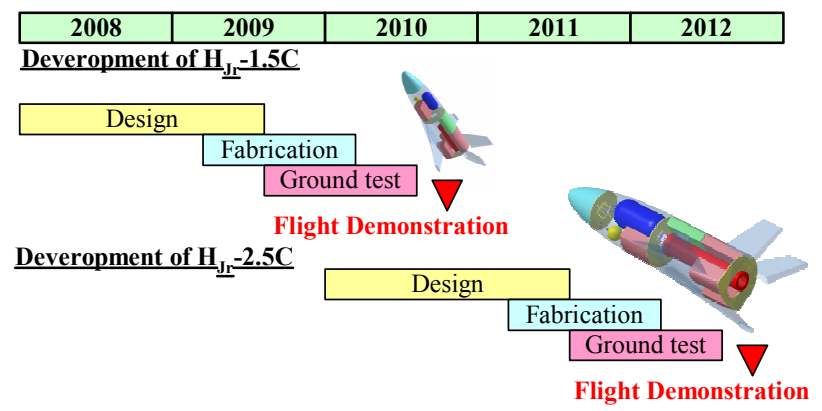

Fig. 13. Development schedule of winged experimental rockets

\section{Summary}

This paper proposes a development project of winged experimental rockets led by the University Consortium. The advantages of the project are flexibility in steering and cost effectiveness to provide many chances of verifications for the innovative ideas, which are necessary to be evaluated in the early phase of research and development stage by means of actual flight tests.

\section{Acknowledgements}

This study was carried out by the contract with JAXA (Japan Aerospace Exploration Agency). The authors would like to thank for valuable contributions to this study from $\mathrm{Mr}$. T. Morito and Dr. S. Ishimoto of JAXA/Space Transportation Program Systems Engineering Office. The research on the high maneuver GPS receiver named GP4020 has been conducted by Associate Prof. Dr. T. Ebinuma of Tokyo University of Marine Science and Technology, and the CFRP structure design and health monitoring system have been conducted by Associate Prof. Dr. H. Murayama and Lecturer Dr. K. Uzawa of the University of Tokyo. The authors would also like to express their gratitude for their kind advices and help.

\section{References}

1) Japan Aerospace Exploration Agency,: JAXA Vision-JAXA 2025-, 2005.

http://www.jaxa.jp/about/2025/index e.html

2) Morito, T. and Ishimoto, S.: Overview of the Researches for Human Space Transportation Systems, in JAXA, Proceedings of the JSASS Annual Meeting, Vol.38th, 2007, pp.39-42. (in Japanese)

3) Inatani, Y.: Recent Progress in Reusable Rocket Vehicle Studies, Invited Lecture, 2007 JSASS-KSAS Joint International Symposium on Aerospace Engineering, Kitakyushu, 2007.

4) Minami, Y. and Tshukamoto, T.: A Subscale Flight Experiment for the Approach and Landing of a Lifting Body Re-entry Vehicle, AIAA 2006-8120, 14th AIAA/AHI Space Planes and Hypersonic Systems and Technologies Conference, 2006.

5) Yonemoto, K.: Reusable Launch Vehicle Experiment Done by Universities, Abstracts of ISAS Space Transport Symposium, 2006, pp.33-36. (in Japanese).

6) Kaji, S., Shida, I., and Hiroki, Y.: Preliminary Flight Experiment Result of Small Winged Experimental Rocket, Proceedings of the Meeting, Kyushu Branch of the Japan Society of Mechanical Engineers, Vol.60th, March 2007, pp.245-246. (in Japanese).

7) Yonemoto, K., Funatsu, K., Hiroki, Y., Kaji, S., and Shida, I.: Status of Preflight Experiment toward the Development of Winged Rocket Test Vehicle, Aeronautical and Space Sciences Japan, Vol.56, No.648, January 2008, pp.8-13. (in Japanese).

8) Yonemoto, K., Aso, S., Kosetsu, Y., and Nagata, H.: Development of Winged Experimental Rocket by University Consortium, $51^{\text {st }}$ Proceedings of the Space Sciences and Technology Conference, 2B11, 2007. (in Japanese)

9) Aso, S., Kosetsu, Y., Miyazawa, Y., Tani, Y., Hokamoto, S., Murozono, M., Yonemoto, K., and Nagata, H.: Technical Problems for the Development of Experimental Winged Rocket by University Consortium, $51^{\text {st }}$ Proceedings of the Space Sciences and Technology Conference, 1C20, 2007. (in Japanese)

10) Inatani, Y., Kawaguchi, J., and Yonemoto, K.: Status of 'HIMES' reentry flight test project, AIAA 90-5230, AIAA Second International Aerospace Planes Conference, 1990.

11) Nagata, H., Ito, M., Maeda, T., Watanabe, M., Uematsu, T., Totani, T. and Kudo, I.: Development of CAMUI hybrid rocket to create a market for small rocket experiments, Acta Astronautica, Volume 59, Issues 1-5, July-September 2006 , pp. 253-258. 